

$\begin{array}{lllllll}J & \mathbf{O} & \mathbf{U} & \mathbf{R} & \mathbf{N} & \mathbf{A} & \mathbf{L}\end{array}$

O F

$\mathbf{P} \mathbf{U}$

B L I C

H E A L T H

\title{
The development of a scale to measure concepts of schizophrenia: experience among Brazilian psychiatrists*
}

Desenvolvimento de escala para medir conceitos de esquizofrenia: experiência entre psiquiatras brasileiros

Darci N. Santos, Robert Blizard and Anthony H. Mann

Instituto de Saúde Coletiva da Universidade Federal da Bahia. Salvador, BA - Brasil (D.N.S.), Section of Epidemiology and General Practices of the Institute of Psychiatry. London, UK (R.B., A.H.M.)

SAN TO S D arci N. The development of a scale to measure concepts of schizophrenia: experience among Brazilian psychiatrists* Rev. Saúde Pública, 32 (3): 201-8, 1998

(c) Copyright Faculdade de Saúde Pública da U SP. Proibida a reprodução mesmo que parcial sem a devida autorização do Editor Científico. Proibida a utilização de matérias para fins comerciais. All rights reserved. 


\title{
The development of a scale to measure concepts of schizophrenia: experience among Brazilian psychiatrists*
}

\section{Desenvolvimento de escala para medir conceitos de esquizofrenia: experiência entre psiquiatras brasileiros}

\author{
Darci N. Santos, Robert Blizard and Anthony H. Mann \\ Instituto de Saúde Coletiva da Universidade Federal da Bahia. Salvador, BA - Brasil (D.N.S.), Section \\ of Epidemiology and General Practices of the Institute of Psychiatry. London, UK (R.B., A.H.M.)
}

\begin{abstract}
Introduction

Among psychiatric disorders schizophrenia is often said to be the condition with the most disputed definition. The Bleulerian and Schneiderian approaches have given rise to diagnostic formulations that have varied with time and place. Controversies over the concept of schizophrenia were examined within European/North American settings in the early 1970s but little has since been reported on the views of psychiatrists in developing countries. In Brazil both concepts are referred to in the literature. A scale was developed to measure adherence to Bleulerian and Schneiderian concepts among psychiatrists working in S. Paulo.

Methodology A self-reported questionnaire comprising seventeen visual analogue-scale statements related to Bleulerian and Schneiderian definitions of Shizophrenia, plus sociodemographic and training characteristics, was distributed to a nonrandomised sample of 150 psychiatrists. The two sub-scales were assessed by psychometric methods for internal consistency, sub-scale structure and testretest reliability. Items selected according to internal consistency were examined by a two-factor model exploratory factor analysis. Intraclass correlation coefficients described the stability of the scale.

Results Replies were received from 117 psychiatrists (mean age 36 (SD 7.9)), 74\% of whom were made and $26 \%$ female. The Schneiderian scale showed better overall internal consistency than the Bleulerian scale. Intra-class correlation coefficients for test-retest comparisons were between 0.5 and 0.7 for Schneiderian items and 0.2 and 0.7 for Bleulerian items. There was no negative association between Bleulerian and Schneiderian scale scores, suggesting that respondents may hold both concepts. Place of training was significantly associated with the respondent's opinion; disagreement with a Bleulerian standpoint predominated for those trained at the University of S. Paulo.
\end{abstract}

* Work carried out at: Section of Epidemiology and General Practice, Institute of Psychiatry, London. Study funded by "Conselho Nacional de Desenvolvimento Científico e Tecnológico/CNPq" (Process n ${ }^{\circ}$ 203310-870). Derived from a PhD thesis "The diagnosis of schizophrenia in S. Paulo, Brazil: the influence of patients culture and clinicians' concepts", submitted to and approved by the University of London in April 1996. Correspondence to: Darci N. Santos - Rua Padre Feijó, 29 - $4^{\circ}$ andar - Canela 40110-170 Salvador, Ba - Brasil. E-mail: darci@ ufba.br Submited on 16.6.1997. Approved on 27.1.1998. 
Conclusions The less satisfactory reliability for the Bleulerian sub-scale limits confidence in the whole scale but on the other hand this questionnaire contributes to the understanding of the controversy over Bleulerian and Schneiderian models for conceptualisation of schizophrenia, the former requiring more inference and therefore being prone to unreliability.

Schizophrenia, diagnosis. Concept formation. Psychiatry, manpower.

\section{Resumo}

Introdução

Foi desenvolvida uma escala para medir aderência ao conceito Bleuleriano e Schneideriano de esquizofrenia entre psiquiatras trabalhando em São Paulo, analisando relações entre variáveis sociodemog ráficas e de formação sobre o escore obtido.

Métodos Questionário contendo escala visual analógica com dezessete enunciados sobre conceitos Schneideriano e Bleuleriano de esquizofrenia, foi distribuído para 150 psiquiatras. As sub-escalas Bleuleriana e Schneideriana foram avaliadas por metódos psicométricos de consistência interna, estrutura das subescalas e confiabilidade test-reteste.

Resultados Completaram o questionário 117 psiquiatras. A subescala Schneideriana demonstrou melhor consistência interna e melhores coeficientes de correlação intraclasse. Não houve associação negativa entre os escores das subescalas. Discordância com o conceito Bleuleriano predominou entre profissionais treinados na USP.

Conclusões A baixa confiabilidade da sub-escala Bleuleriana limita a confiabilidade do instrumento como um todo, embora contribua para a discussão dos modelos em questão. Argumenta-se que o modelo Bleuleriano, por exigir maior inferência, torna-se propenso a baixa confiabilidade.

Esquizofrenia, diagnóstico. Formação de conceito. Psiquiatria, recursos humanos.

\section{INTRO DUCTION}

Among psychiatric disorders schizophrenia is often said to be the condition whose definition is most disputed $^{7}$. Diverse theoretical viewpoints as to the nature of this condition are available to psychiatrists, and adherence to one or another will affect clinical practice and, specifically, diagnosis. Variations in diagnostic rates may thus be explained by understanding the concepts that are held, concerning the conditions.

Bleuler ${ }^{2}$ is generally regarded as having widened the original Kraepelian concept of schizophrenia. The symptoms he believed to be essential to diagnose the disorder - looseness of association, blunting of affect, autism and ambivalence - give wide scope for differing clinical interpretation ${ }^{3}$. On the other hand, Schneider's phenomenological definition of schizophrenia used symptoms which can be more reliably elicited - hallucinations, delusions and deficits of ego boundary ${ }^{9}$. Bleuler ${ }^{2}$ believed that the intrapsychic process of associative splitting was central to this group of psychotic disorders. He explained the existence of delusions and hallucinations accessory symptoms - as a product of the complexes. Schneider ${ }^{9}$ did not subscribe to this theoretical formulation, but postulated delusions and hallucinations as important markers for diagnosis on the part of clinicians.

These two relatively distinct approaches to schizophrenia have given rise to diagnostic formulations that have varied with time and place. European psychiatry embraced the Schneiderian concept; Bleuler's influence was more apparent in the United States ${ }^{3,6}$. The controversies over the concept of schizophrenia were examined within 
European/North American settings in the early 1970s, showing a broader concept in the United States at that stage than in the UK, in keeping with these different influences ${ }^{4}$.

Little has since been reported on the views of psychiatrists in developing countries. In Brazil, Bleulerian and Schneiderian views are both commonly held. Shirakawa ${ }^{10}$ and Bastos ${ }^{1}$, for example, express a Bleulerian viewpoint. Shirakawa ${ }^{10}$ suggests that clinicians may diagnose this disorder according to features such as autism, ambivalence, withdrawal, delusions and nonsystematised hallucinations. In Bastos' view, rapport and abnormal expression by the patient are features for diagnosis; schizophrenia may present with a nonspecific clinical picture which becomes clear later in its course ${ }^{1}$. However, Schneider's first rank symptoms have also been suggested as diagnostic criteria $^{11}$. Sougey reported a $65 \%$ rate for these symptoms amongst seventy inpatients diagnosed as schizophrenic according to ICD9.

Seven hundred and seventy-two medical doctors in the state of S. Paulo have specialised in psychiatry by attending one of the recognised training centres. The orientation of most centres is biological, although the psychodynamic approach is also taught ${ }^{5}$.

The measurement of psychiatrists' concepts of schizophrenia has not been carried out systematically by questionnaire before. The current study attempted to develop a scale to measure adherence to Bleulerian and Schneiderian concepts among psychiatrists in Brazil, aiming at an assessment of their influence on the diagnosis of schizophrenia. Brazil is useful for this exercise since both concepts are likely to be widely held. The development and refinement of this scale using data from Brazilian respondents is described in the present paper.

\section{SU BJECT AND METHOD}

\section{Development of the Bleuler Schneider Concepts Q uestionnaire (BSCQ ) \\ Devising the $Q$ uestionnaire}

The questionnaire was designed for self-reporting*. In constructing the questionnaire the main purpose was to detect the conceptual model of the respondent in relation to diagnosis. A large number of items concerning features of schizophrenia were drawn from psychiatry textbooks. To ensure face validity, the final selection among these items was made by a panel of three British schizophrenia researchers. Seventeen items, nine representing the
Bleulerian and eight the Schneiderian school of thought, were chosen. Each statement was followed by a $10 \mathrm{~cm}$ visual analogue scale (VAS), anchored at one end by 'strongly agree' and at the other end by 'strongly disagree'. The introduction to the questionnaire contained guidance for respondents on how to use the VAS.

\section{Surveying the Psychiatrists}

One hundred and fifty copies of the seventeen-item scale were distributed by the main investigator, who visited psychiatrists at their places of work in S. Paulo. These comprised five outpatient clinics, two emergency psychiatric services, three mental hospitals in the public sector, and three teaching hospitals. Participation was based on the availability of psychiatrists on the day of the visit. Respondents were also asked to complete a questionnaire covering their sociodemographic characteristics and the professional training they had received. Twenty-one psychiatrists agreed to answer the questionnaire for a second time one month later, so that the correlation between scores on the two occasions could be compared to measure the test-retest reliability of the instrument.

\section{Data Analysis}

The BSCQ VAS were measured in millimetres. Statistical analysis was carried out with the Statistical Package for the Social Sciences and involved the following operations:

A. Simple descriptive statistics were calculated for each demographic, training and attitudinal item. Mean scores and their $95 \%$ confidence interval were calculated for the BSCQ items and are shown in Table 1.

$B$. The responses from the psychiatrists to the eight Schneiderian items and the nine Bleulerian were further refined. The following statistical procedures were applied.

A skewness test, achieved by dividing skewness by the standard error of skew for each item, was applied to eliminate those with great departure from symmetry. Items with a ratio equal to or larger than two were eliminated.

Cronbach Alpha Coefficients were calculated for the Bleulerian and Schneiderian scales to check that each item was contributing consistently to a unitary scale.

The items selected according to internal consistency were then submitted to an exploratory factor analysis on the basis of a two-factor model, the factors being extracted by the method of principal components. This procedure was carried out to identify common factors that would help classify Bleulerian and Schneiderian variables based on statistical criteria.

The stability of the scale in terms of respondent's consistency across time was described by the intraclass correlation coefficients based upon one-way analysis of variance.

$C$. The most stable items were then summed to give a composite Bleuler and Schneider score for each 
psychiatrist (low values meant agreement and high values disagreement). The Bleuler and Schneider scale scores were plotted against one another. The difference between the Bleuler and Schneider scale scores produced a single variable to distinguish the psychiatrists. A high positive score would indicate a weak Bleulerian affiliation and a low score a stronger Bleulerian affiliation. Scores around zero would indicate that the respondents scored at the same level on both concepts. The Student $\mathbf{t}$ test for independent groups was carried out to examine the association between psychiatrists' conceptual variables and gender, year graduated, training additional to rotation and psychiatric college of the respondents. Age was defined as years at last birthday and stratified into two groups. Year of graduation from medical school was categorised as preor post-1980. Experience of Rotation through a number of psychiatric posts was the criterion for classification of a respondent as a trained psychiatrist. The place of training was first classified as inside or outside S. Paulo state [three respondents trained outside $\mathrm{S}$. Paulo state were excluded]. Then training was classified as being either at one of eight colleges in S. Paulo or at the University of S. Paulo (USP). Each respondent was also screened as having additional training: academic or psychotherapeutic.

\section{RESU LTS}

\section{Sample Characteristics}

A total of 117 psychiatrists (78\%) completed the BSCQ. Eighty-six (74\%) men and 31 (26\%) women responded. Their mean age was 36 years (standard deviation, SD 7.9). Sixty-six doctors (56\%) of the sample had less than ten years of experience since qualification. Atotal of ninety-six (82\%) were trained in a rotation, attending teaching hospitals inside $\mathrm{S}$. Paulo state. The majority - fifty-three (55\%) - were trained at USP, and forty-three (45\%) at one of the other colleges. Additional training, such as in research or psychotherapy, was carried out by forty-four respondents (46\%). Information regarding the thirtythree doctors who did not respond to the questionnaire was limited to their current place of work.

The mean scores and a 95\% confidence interval (CI) of all respondents for each Bleulerian and Schneiderian VAS item was calculated (Table 1). None showed a clear bimodal distribution, thus

Table 1 - Mean scores (m) and standard deviation (Sd) with 95\% Cl, for Brazilian psychiatrists on the BSCQ items. Higher values indicating greater disagreement with statement.

\begin{tabular}{|c|c|c|c|c|}
\hline Bleulerian $(B)$ and Schneiderian $(S)$ items & $\mathbf{m}$ & $\mathrm{Sd}$ & $95 \% \mathrm{Cl}$ & $\mathrm{n}$ \\
\hline $\begin{array}{l}\text { 1(B). Autism, ambivalence, affective blunting and thought disorder are } \\
\text { sufficient to diagnose schizophrenia (Sz).* }\end{array}$ & 35 & 30 & $29 \prec->40$ & 113 \\
\hline $\begin{array}{l}2(B) . \text { Impoverishment of affect and disturbances in personal contact/rapport are } \\
\text { fundamental to characterising Sz.** }\end{array}$ & 45 & 30 & $39 \prec->51$ & 113 \\
\hline $\begin{array}{l}3(B) \text {. Ambivalence and depersonalisation are essential features for Sz diagnosis.** } \\
4(B) \text {. The split of several psychic functions is one of the most }\end{array}$ & 61 & 31 & $54<->66$ & 113 \\
\hline important characteristics in Sz.* & 35 & 28 & $29 \prec->40$ & 113 \\
\hline 5 (B). Ambivalence and autism constitute the basic symptoms in $\mathrm{Sz} .{ }^{* *}$ & 44 & 30 & $38<->49$ & 113 \\
\hline \multicolumn{5}{|l|}{$6(B)$. Looseness of association and inappropriate } \\
\hline affect are typical features of $\mathrm{Sz} .{ }^{* *}$ & 52 & 29 & $45 \prec->56$ & 113 \\
\hline 7 (B). Loss of capacity for modulation of the affects is indicative of Sz. & 59 & 30 & $52 \prec->64$ & 113 \\
\hline 8 (B). Persistent affective indifference and affective rigidity would indicate Sz. & 56 & 28 & $50<->60$ & 114 \\
\hline $\begin{array}{l}9 \text { (B). Poor rapport, autism and incomprehensible behaviour can lead to } \\
\text { diagnose Sz before unequivocal psychotic symptoms were present.* }\end{array}$ & 41 & 31 & $35 \prec->47$ & 113 \\
\hline 10 (S). Schneider's first rank symptoms are key symptoms of Sz.* & 74 & 25 & $69 \prec->79$ & 113 \\
\hline $\begin{array}{l}11 \text { (S). Having excluded an organic cause from a first acute episode, } \\
\text { diagnosis can be made on florid symptoms alone. }\end{array}$ & 60 & 35 & $53<->66$ & 113 \\
\hline $\begin{array}{l}12 \text { (S). Diagnostic criteria of Sz can only be based on specific types of } \\
\text { hallucinations and delusions.* }\end{array}$ & 82 & 24 & $77 \prec->86$ & 113 \\
\hline $\begin{array}{l}13(\mathrm{~S}) \text {. Thought insertion, thought withdrawal and thought broadcasting are } \\
\text { basic phenomena for the diagnosis of } \mathrm{Sz} . * *\end{array}$ & 49 & 31 & $42 \prec->54$ & 113 \\
\hline $\begin{array}{l}14(S) \text {. Auditory hallucinations constituted by voices discussing the subject } \\
\text { in the third person is pathognomonic of } S z . * *\end{array}$ & 58 & 34 & $51<->64$ & 113 \\
\hline $\begin{array}{l}15(S) \text {. The sensation of feelings impulses or acts being experienced or } \\
\text { carried out under external control is pathognomonic of } S z .^{* *}\end{array}$ & 53 & 34 & $46<->59$ & 113 \\
\hline $\begin{array}{l}16 \text { (S). Psychotic symptoms other than Schneider's first rank are } \\
\text { not indicative of Sz.* }\end{array}$ & 67 & 30 & $61<->72$ & 113 \\
\hline $\begin{array}{l}17(S) \text {. If first rank symptoms are present in a psychotic condition in the } \\
\text { absence of organic pathology, it is Sz. } * *\end{array}$ & 45 & 33 & $38<->51$ & 113 \\
\hline
\end{tabular}

* Eliminated items by skewness test. $\quad$ ** Selected items for the final scales 
making it impossible to identify two different groups of psychiatrists. The mean for the nine Bleulerian items ranged from 35 to 61 . The large standard deviations (28 $\geq 31)$ suggest a large variation among the observations. Across the Schneiderian items mean values varied from 45 to 82 , and standard deviation from 24 to 35 .

\section{Refining the Q uestionnaire}

- Items 10, 12 and 16 of the Schneider scale and items 1,4 , and 9 of the Bleuler scale were eliminated on account of Skewness test results.

- When the Cronbach Alpha coefficient was calculated for the remaining five Schneiderian and six Bleulerian items, an Alpha value of .62 was found for the Bleulerian subscale (Table 2). No item-total correlation was negative but the highest correlation was .43. With the elimination of both item 8 and item 7, Cronbach Alpha improved to .64. Cronbach's Alpha value for the five Schneiderian items was .61 (Table 2). By eliminating item number 11 - the only one with a negative correlation - the Alpha value increa-sed to .73 . Both scales were thus reduced to four items each

-Examination of these final four-item Bleulerian and Schneiderian scales by the two-factor model succeeded in identifying two common factors with a clear pattern to explain the variables. Factor 1 had a higher correlation with Schneiderian items, and factor 2 with Bleulerian items. No item achieved high loadings for both factors (Table 3). A plot of the total

Table 2 - Item-total correlation and Alpha $(\alpha)$ values for the first calculations of Bleulerian and Schneiderian scales.

\begin{tabular}{|c|c|c|c|c|c|}
\hline \multicolumn{3}{|c|}{ Bleulerian scale $\alpha=.62$} & \multicolumn{3}{|c|}{ Schneiderian scale $\alpha=.61$} \\
\hline Item & $\begin{array}{l}\text { Item-total } \\
\text { Correlation }\end{array}$ & $\begin{array}{c}\alpha \text { If item deleted } \\
\text { Correlation }\end{array}$ & Item & Item-total & $\alpha$ If item deleted \\
\hline 2 & .43 & .54 & 11 & .00 & .73 \\
\hline 3 & .35 & .57 & 13 & .32 & .57 \\
\hline 5 & .37 & .56 & 14 & .56 & .44 \\
\hline 6 & .33 & 58 & 15 & .59 & .42 \\
\hline 7 & .37 & .56 & 17 & .44 & .51 \\
\hline 8 & .23 & .62 & - & - & - \\
\hline
\end{tabular}

Table 3 - Factor loadings for the eight items, after varimax rotation according to Bleulerian and Schneiderian classification

\begin{tabular}{lrrr}
\hline Item & Factor 1 & Factor 2 & Classification \\
\hline 2 & .13177 & .62734 & Bleulerian \\
3 & -.13496 & .70870 & Bleulerian \\
5 & -.07000 & .77781 & Bleulerian \\
6 & .12432 & .65712 & Bleulerian \\
13 & .58196 & -.10617 & Schneiderian \\
14 & .89337 & .3880 & Schneiderian \\
15 & .90739 & -.03420 & Schneiderian \\
17 & .53713 & .23849 & Schneiderian \\
\hline
\end{tabular}

variance associated with each factor showed a clear break between the slope of factors 1 and 2 and the other factors.

- As an assessment of the stability of the scale, the intraclass coefficients were calculated. The four Schneiderian items lay between .5 and .7 , but only one Bleulerian item attained a satisfactory consistency (Table 4).

\section{Associations with Scale Scores}

The mean value for the composite score on the

Table 4 - Intraclass correlation coefficient (ICC) for test-retest reliability by 21 psychiatrists on the final Bleulerian $(B)$ and Schneiderian $(S)$ items together with composite scores.

\begin{tabular}{lrc}
\hline Item & Variable & ICC \\
\hline $2(B)$ & Impoverishment \& disturbances in personal contact/ rapport & .22 \\
$3(B)$ & Ambivalence and depersonalisation as essential features in Sz & .34 \\
$5(B)$ & Ambivalence and autism are the basic symptoms in Sz & .24 \\
$6(B)$ & Looseness of association and inappropriate affect, typical features of Sz & .70 \\
$13(S)$ & Thought insertion, thought withdrawal and thought broadcasting & .68 \\
$14(S)$ & Auditory hallucinations by voices in the third person & .72 \\
$15(S)$ & Feelings impulses or acts experienced under external control & .69 \\
$17(S)$ & Symptoms of the first rank without organic pathology & .54 \\
\hline Bleulerian scale & Composite score from the Bleulerian items & .37 \\
Schneiderian scale & Composite score from the Schneiderian items & .77 \\
Single conceptual variable & Difference between both composite scores & .66 \\
\hline
\end{tabular}


four-item Bleulerian and Schneiderian scales were respectively: $(201,95 \% \mathrm{CI}=183 \longleftrightarrow 218)$ and $(207$, $95 \% \mathrm{CI}=186 \longleftrightarrow 228)$. The plot of these two scores for each psychiatrist shows a scattered distribution with no discernible association between the two measures. The difference between the Bleulerian and Schneiderian composite scores had a mean of (-6, $95 \% \mathrm{CI}=-33 \longleftrightarrow 21)$. There was no association of the difference score with age, gender, year graduated, psychotherapeutic and academic training undertaken by the respondents. Only place of training was respondents were less inclined to a Bleulerian view. Much lower test-retest reliability and internal consistency was found for the scale measuring the Bleulerian concept.

\section{Discussion of Methods}

There are methodological limitations to consider. These arise from uncertainty about accuracy of attitude measures, selection bias of the items reflecting a Schneiderian view, poor reliability of Bleulerian

Table 5 - Mean scores $(\mathbf{m})$ of the Bleulerian and Schneiderian four-item final scales by characteristics of the doctors with $95 \% \mathrm{Cl}$ for mean difference. $\mathrm{N}=96$.

\begin{tabular}{|c|c|c|c|c|c|}
\hline Variable & Groups & $\mathrm{N}$ & $m$ & $95 \% \mathrm{Cl}$ & $P$ \\
\hline \multirow{8}{*}{ Bleuler } & Aged $\leq 35$ & 59 & 207 & $(-16<->55)$ & .28 \\
\hline & $\geq 36$ & 34 & 188 & & \\
\hline & $\begin{array}{l}\text { Male } \\
\text { Female }\end{array}$ & $\begin{array}{l}69 \\
24\end{array}$ & $\begin{array}{l}198 \\
207\end{array}$ & $(-48<->31)$ & .66 \\
\hline & Graduated before 1980 : & 32 & 184 & $(-61<->10)$ & .16 \\
\hline & $\begin{array}{c}\text { After 1980: } \\
\text { Academic Training }\end{array}$ & $\begin{array}{l}61 \\
25\end{array}$ & $\begin{array}{l}209 \\
210\end{array}$ & $(-25<->69)$ & .35 \\
\hline & Psychotherapeutic & 23 & 188 & & \\
\hline & USP trained & 52 & 221 & $(12 \prec->80)$ & .00 \\
\hline & N ot U SP trained & 41 & 174 & & \\
\hline \multirow{7}{*}{ Schneider } & $\begin{array}{l}\text { Aged } \leq 35 \\
\geq 36\end{array}$ & $\begin{array}{l}58 \\
35\end{array}$ & $\begin{array}{l}211 \\
195\end{array}$ & $(-26<->59)$ & .44 \\
\hline & $\begin{array}{l}\text { Male } \\
\text { Female }\end{array}$ & $\begin{array}{l}70 \\
23\end{array}$ & $\begin{array}{l}200 \\
220\end{array}$ & $(-68<->28)$ & .42 \\
\hline & Graduated before 1980 : & 33 & 192 & $(-64<->23)$ & .36 \\
\hline & $\begin{array}{c}\text { After 1980: } \\
\text { Academic Training }\end{array}$ & $\begin{array}{l}60 \\
25\end{array}$ & $\begin{array}{l}212 \\
204\end{array}$ & $(-24<->90)$ & .25 \\
\hline & Psychotherapeutic & 23 & 171 & & \\
\hline & U SP trained & 53 & 194 & $(-68<->16)$ & .22 \\
\hline & Not U SP trained & 40 & 220 & & \\
\hline \multirow{7}{*}{$\begin{array}{l}\text { Bleuler/Schneider } \\
\text { Difference }\end{array}$} & Aged $\leq 35$ & 58 & -3 & $(-49<->64)$ & .78 \\
\hline & $\geq 36$ & 34 & -11 & & \\
\hline & Male & 69 & -4 & $(-56<->71)$ & .81 \\
\hline & $\begin{array}{c}\text { Female } \\
\text { Graduated before 1980: }\end{array}$ & $\begin{array}{l}23 \\
32\end{array}$ & $\begin{array}{l}-12 \\
-13\end{array}$ & $(-68<->47)$ & 72 \\
\hline & $\begin{array}{c}\text { After 1980: } \\
\text { Academic Training }\end{array}$ & $\begin{array}{l}60 \\
24\end{array}$ & $\begin{array}{r}-2 \\
.75\end{array}$ & $(-92<->59)$ & .66 \\
\hline & Psychotherapeutic & 23 & 17 & & \\
\hline & USP trained & 52 & 23 & $(15<->123)$ & $.01 *$ \\
\hline
\end{tabular}

USP - U niversity of S. Paulo

significantly associated with this difference score, more disagreement with a Bleulerian standpoint predominating for those trained at the USP (Table 5).

\section{DISCUSSION}

\section{Main Findings}

The psychiatrists in this study did not hold a concept of schizophrenia that was exclusively Bleulerian or Schneiderian in type; however, USP trained items, non-randomisation and over-use of the sample.

Problems of accuracy are involved in the construction and evaluation of any measurement tool. To the best of our knowledge this report is the first to assess Brazilian psychiatrists' attitudes towards Bleulerian and Schneiderian definitions of schizophrenia. It was expected that there should be a degree of reciprocity between doctors' agreements with Bleuler/Schneider standpoints. This was not the case, however, since the plot of the scores showed a scattered distribution with no negative association 
between the two scales. It could be argued that the statements were, therefore, not good differentiators between Bleulerian and Schneiderian viewpoints, even though the initial item selection was made on the advice of three researchers expert in schizophrenia. These advisors could have been biased as they worked within the British tradition, aligned with the Schneiderian point of view. Nevertheless the two sets of conceptual statements did represent precisely the literature on these schools of thought, their construct validity supported by a two-dimensional exploratory factor analysis model.

An important point to be made concerns the different psychometric performance of the two sets of items. The distinction between the contribution of items to overall internal consistency was clearer for the Schneiderian than the Bleulerian scale. Schneiderian items correlated more highly with each other than Bleulerian items. The alpha values were, however, good enough to imply that each scale was measuring a unitary dimension, and the principal component analysis demonstrated two large factors accounting for $53 \%$ of the variance. Each factor had very large positive loadings on different sets of items, creating a clear distinction between Bleulerian and Schneiderian statements. Different performance for internal consistency measures on both scales may, therefore, reflect the ingredients of each scale, the Bleuler scale being less clear-cut.

When the items were scored for the second time, less satisfactory repeatability was found amongst the Bleulerian items. The intraclass correlation coefficients suggested that more intra subject variability was found for these items. The poor internal consistency and repeatability of the items measuring the Bleulerian concept of schizophrenia tends to confirm its vagueness, and perhaps explains its loss of significance in present systems of classification $^{8}$. However, test reliability of the total eight-item scale was shown to be satisfactory.

Sampling concerns must also be considered. The possible bias involving the surveying process in this study should be borne in mind, as representativeness cannot be claimed. Despite a $78 \%$ response rate, nonresponding psychiatrists might have differed systematically as regards their Bleulerian/ Schneiderian viewpoint. On the other hand, taking into account participation of teaching hospital psychiatrists and those working in a diversity of clinical settings, the sample chosen probably gave a reasonable indication of the range of local psychiatrists' views.

\section{Discussion of Findings' Implications}

Despite low reliability for the Bleulerian subscale presenting a problem for the complete usefulness of this scale, a good reliability coefficient was found for the single conceptual variable consisting of the difference of scores between the two sub-scales. The association between being trained at the USP expressing higher disagreement with a Bleulerian conceptualisation is a consistent finding since this college has a traditional academic orientation. It is a World Health Organization collaborating center for training and research in mental health, which runs courses on the Portuguese version of the Present State Examination on a regular basis.

The exercise has been partially successful, producing a four-item scale that points to a Schneiderian viewpoint. As the Bleulerian scale is unsatisfactory, further consideration of the items themselves and their wording is needed - checking with those who favour this concept. If two scales of equal reliability could be established, then a study in a new and random sample of psychiatrists is necessary to confirm the factor structure. Subsequently, the ability of the scale to predict diagnostic behaviour by comparison with a research diagnosis should be verified. This in turn could also enable us to predict psychiatrists' behaviour in response to patients with psychotic symptoms suggesting schizophrenia.

\section{ACKN O W LED G EMENTS}

To the psychiatrists who completed the questionnaire. Thanks are also due to Dr J. van Os, Dr G. Lewis, Dr M. Prince, Dr G. Busatto and Mr N. Hunter for their contributions. 


\section{REFEREN CES}

1. BASTOS, O. Distúrbios esquizofrênicos J. Bras. Psiquiatr., 37: 71-5, 1988.

2. BLEULER, E. Dementia Praecox or the group of schizophrenias. New York, International Universities Press, 1950.

3. COOPER, J.E. Concepts of schizophrenia in the United States of America and in Great Britain; a summary of some studies by the U.S-U.K. Diagnostic Project. In: Lader, M.H., ed. Studies of schizophrenia. London, Headley Brothers, 1972. p. 19-24.

4. COOPER, J.E. et al. Psychiatric diagnosis in New York and London. A comparative study of mental hospital admissions Maudsley Monogr., 20:47-54, 1972.

5. IACOPONI, E. et al. Brazil: a giant wakes up to progress and inequality. In: Appleby, L. \& Araya, R., ed. Mental health services in the global village. London, Gaskell, 1991.

6. KENDELL, R.E. Schizophrenia. In: Kendell, R.E. \&
Zealley, A.K., ed. Companion to psychiatric studies. Edinburgh, Churchill-Livingstone, 1988. p. 310-34.

7. SARTORIUS, N. et al. Towards an international definition of schizophrenia: a report from the International Pilot Study of Schizophrenia. In: Lader, M.H., ed. Studies of schizophrenia. London, Headley Brothers, 1972. p. 25-8.

8. SASS, H. The classification of schizophrenia in the different diagnostic systems. In: Hafner, H.; Gattaz, F.W.; Janzarik, W., ed. Berlin Spring-Verlag, 1987. p. 19-28.

9. SCHNEIDER K. Clinical psychopathology. New York, Grune \& Straton, 1950.

10. SHIRAKAWA, I. Esquizofrenia: histórico e conceito. $J$. Bras. Psiquiatr., 38: 154-6, 1989.

11. SOUGEY, E.B. Frequiência dos sintomas de primeira ordem de Kurt Schneider numa população de esquizofrênicos do Nordeste brasileiro. Rev. ABP APAL, 9: 151-6, 1987. 